\title{
Accuracy assessment of a PION TCl pump based on international standards
}

\section{Doh', Seok Hwan Lee ${ }^{2}$, Yong-Hun Lee ${ }^{3}$, Bokyoung Jeon ${ }^{3}$, Byung-Moon $\mathrm{Choi}^{3}$, and Gyu-Jeong $\mathrm{Noh}^{3,4}$}

${ }^{1}$ Center for Medical Metrology, ${ }^{2}$ Center for Thermometry and Fluid Flow Metrology, Korea Research Institute of Standards and Science (KRISS), Daejeon, Departments of ${ }^{3}$ Anesthesiology and Pain Medicine, ${ }^{4}$ Clinical Pharmacology and Therapeutics, Asan Medical Center, University of Ulsan College of Medicine, Seoul, Korea

\section{Corresponding author}

Byung-Moon Choi, M.D., Ph.D.

Department of Anesthesiology and Pain Medicine, Asan Medical Center, University of Ulsan College of Medicine, 88 Olympic-ro 43-gil, Songpa-gu, Seoul 05505, Korea Tel: 82-2-3010-1704

Fax: 82-2-3010-6790

E-mail: byungmoonchoi7@gmail.com ORCID

https://orcid.org/0000-0002-6561-8851

Background: Inaccuracies associated with target-controlled infusion (TCl) delivery systems are attributable to both software and hardware issues, as well as pharmacokinetic variability. However, little is known about the inaccuracy of the syringe pump operating in TCl mode. This study aimed to evaluate the accuracy of the TCI pump based on international standards.

Methods: A test apparatus for accuracy evaluation of a syringe pump (PION TCl${ }^{\circledR}$, Bionet Co. Ltd.) was designed to apply the gravimetric method. Pump accuracy was evaluated in terms of deviation defined by the following equation: infusion rate deviation (\%) =

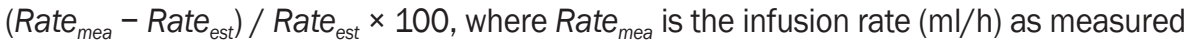
by the gravimetric system, and Rate est $_{\text {is }}$ the infusion rate $(\mathrm{ml} / \mathrm{h})$ as estimated by the pump. An infusion rate representing $\mathrm{TCl}$ mode was determined from previous clinical trial data which evaluated the predictive performance of the pharmacokinetic model. The PION TCI pump used in that clinical trial was used to evaluate accuracy of the syringe pump. The distribution of infusion rates obtained from the clinical trial was calculated, and the median value of the distribution was determined as the representative value.

Results: The representative infusion rate representing $\mathrm{TCl}$ mode was $31 \mathrm{ml} / \mathrm{h}$, at which the infusion rate deviation was $4.5 \pm 1.6 \%$.

Conclusions: The inaccuracy of the syringe pump contributing to $\mathrm{TCl}$ system inaccuracy is insignificant.

Keywords: Accuracy; Infusion; Pump.

\section{INTRODUCTION}

Target-controlled infusion (TCI) is an administration method that changes the infusion rate to maintain target concentration and is currently used in anesthesia and sedation $[1,2]$. For an accurate target effect-site concentrationcontrolled infusion, a dedicated syringe pump with pharmacokinetic models and blood-brain equilibration rate constant $\left(k_{e 0}\right)$ is required [3]. The pharmacokinetic model included in the TCI system consists of population typical values of each pharmacokinetic parameter and covariates describing some of the inter-individual variability [4], that is, the inter-individual variability of pharmacokinetic parameter not explained by covariates (expressed as ETA in the control stream of nonlinear mixed effects modeling) and model error (expressed as SIGMA) are not reflected in the TCI system $[4,5]$. For this

This is an Open Access article distributed under the terms of the Creative Commons Attribution Non-Commercial License (http://creativecommons.org/licenses/by-nc/4.0) which permits unrestricted non-commercial use, distribution, and reproduction in any medium, provided the original work is properly cited. 
reason, when a new pharmacokinetic model is developed, it is necessary to evaluate the accuracy of the TCI system in which the model is programmed prior to deployment in clinical practice [6]. The evaluation criteria for the overall predictive performance of the TCI system were offered by Varvel et al. [7]. Briefly, the inaccuracies associated with TCI delivery system are attributable to both software and hardware issues as well as pharmacokinetic variability. In terms of software, inaccuracies are due to errors associated with incorrect implementation of the pharmacokinetic model, which can be easily corrected. However, little is known about the inaccuracy of the syringe pump operating in TCI mode as there is no accuracy criterion for TCI mode operation of the syringe pump according to International Standards IEC 60601-2-24 [8]. Considering the recent advances in syringe pump technology, the impact of the pump on inaccuracies in the TCI delivery system may be insignificant. However, it is necessary to quantitatively evaluate the accuracy of the syringe pump.

Therefore, this study aimed to evaluate the accuracy of the syringe pump operating in TCI mode based on international standards.

\section{MATERIALS AND METHODS}

The accuracy of medical electrical equipment including volumetric or syringe pump is normally assessed by administering a test solution at a constant rate over a period of time and subsequently measuring the weight of the actually administered solution $[8,9]$. However, because the TCI mode can be interpreted as variable infusion rates, it is not feasible to apply the gravimetric method to a syringe pump operating in TCI mode. Nevertheless, the accuracy of a syringe pump operating in TCI mode can be assessed based on international standards if the infusion rate representing the TCI mode can be determined. In this in vitro study, we used the infusion rate representing the TCI mode, which was derived from the results of a previous study that evaluated the predictive performance of a new pharmacokinetic model [6]. The accuracy of the pump was thus evaluated using the gravimetric method based on the international standard at the predefined infusion rate. Exemption of approval for this study was granted by the institutional review board at Asan Medical Center (Seoul, Korea).

\section{Determination of an infusion rate representing TCl mode}

When a new pharmacokinetic model is developed, an external validation must be performed prior to deployment of the model in clinical practice [10]. The results of evaluating the predictive performance of a new pharmacokinetic propofol model-Choi model-for use in underweight patients during target-controlled infusion have recently been published [6]. These clinical trial data were used to determine an infusion rate representing the TCI mode in the current study [6]. A brief introduction to this clinical test method is as follows [6]. Propofol was infused with TCI syringe pump (PION TCI ${ }^{\circledR}$, Bionet Co. Ltd., Korea), which was connected to a personal computer (PC) by an RS232c cable and controlled by TCI software (Asan pump, version 2. 1. 3, Bionet Co. Ltd., http:// www.fit4nm.org/download). Plasma concentration, effectsite concentration, dose infused, and infusion rate data were recorded at $10 \mathrm{~s}$ intervals and stored in comma-separated values ("csv") format. Pharmacokinetic parameters and blood-brain equilibration rate constant $\left(k_{e 0}\right)$ of the new pharmacokinetic model were programmed into the Asan pump.

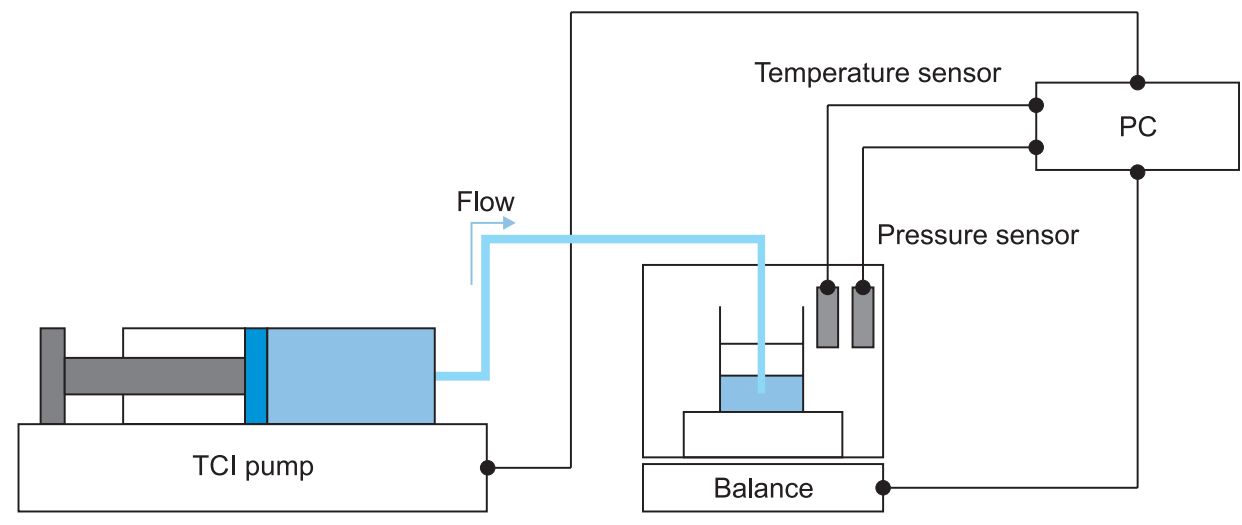

Fig. 1. Experimental setup for accuracy evaluation of the PION TCl pump. PC: personal computer, TCl: targetcontrolled infusion. 
The order of the target $C e$ values of propofol was 2.5, 3, 3.5, $4,4.5$, and $2 \mu \mathrm{g} / \mathrm{ml}$, with each concentration maintained for at least 10 min after reaching pseudo-steady-state between blood and brain. The distribution of infusion rates obtained from the clinical trial was calculated, and the median value of the distribution was determined as the representative value. The PION TCI pump used in the clinical trial was used for the accuracy evaluation of syringe pump [6].

\section{Accuracy test of a syringe pump}

We constructed a test apparatus for accuracy evaluation of a TCI syringe pump (PION TCI ${ }^{\circledR}$, Bionet Co. Ltd.) [8]. A schematic experimental setup is presented in Fig. 1. An infusion rate representing TCI mode was determined from previous clinical trial data which evaluated the predictive performance of the pharmacokinetic model [6]. Water in a syringe was infused at the representative infusion rate into a measurement beaker on the balance (XPE 206 DR, MettlerToledo, USA) with a resolution of $5 \mu \mathrm{g}$. To minimize liquid loss to evaporation, an evaporation trap was installed on the beaker. Pressure and temperature sensors were installed in the measurement beaker to obtain precise water density to convert water mass to volume. All measurement equipment and sensors were calibrated and had traceability to National Standards in Republic of Korea. Pressure and temperature data were collected on a laptop computer for offline analysis. After maintaining an infusion rate for at least $10 \mathrm{~min}$, we observed changes in the beaker weight during a $90 \mathrm{~s}$ infusion, repeated 5 times with a minimum time interval of $10 \mathrm{~min}$. All experiments were performed with sterile, disposable $50 \mathrm{ml}$ BD infusion syringes, which are identical to the syringes used in the clinical trial [6]. Pump accuracy was evaluated in terms of deviation as defined by the following equation $[8,9]$ :

$$
\text { Infusion rate deviation }(\%)=\frac{\left(\text { Rate }_{\text {mea }}-\text { Rate }_{\text {est }}\right)}{\text { Rate }_{\text {est }}} \times 100
$$

where, Rate $_{\text {mea }}$ is the infusion rate $(\mathrm{ml} / \mathrm{h})$ as measured by the gravimetric system, and Rate $_{\text {est }}$ is the infusion rate $(\mathrm{ml} / \mathrm{h})$ as estimated by the pump.

The Rate $_{\text {mea }}$ is defined by the following equation:

$$
\text { Rate }_{\text {mea }}=\frac{\varepsilon \times m}{\rho \times t}
$$

where, $\varepsilon$ is the buoyancy correction factor set at 1.00105 [11], $m$ is the mass of the collected water $(g), \rho$ is the density of water $\left(\mathrm{kg} / \mathrm{m}^{3}\right)$, and $t$ is elapsed time $(s)$. The Rate mea $_{\text {was }}$ repeated five times and the mean value was used to calculate the infusion rate deviation. For the calculation of measurement uncertainty of Rate $_{\text {mea }}$, we used uncertainty results from a previous study for the balance, long term stability, and evaporation loss [9].

\section{Statistical analysis}

Statistical analyses were conducted using R (version 3. 5. 2, R Foundation for Statistical Computing, Austria) or SigmaStat version 3. 5 for Windows (Systat Software, Inc., USA). Data are expressed as mean \pm standard deviation (SD) for normally distributed continuous variables and as median (25-75\%) for non-normally distributed continuous variables.

\section{RESULTS}

In this in vitro study evaluating the pump accuracy, the infusion rate representing TCI mode was derived from the 15,693 infusion rate data from a previous clinical study [6]. The frequency distribution of the infusion rate data during propofol administration using a PION TCI pump from the induction of anesthesia to the time of the last blood sampling is presented in Fig. 2. The distribution did not follow the normal distribution, and the median (25-75\%) infusion rate was 31

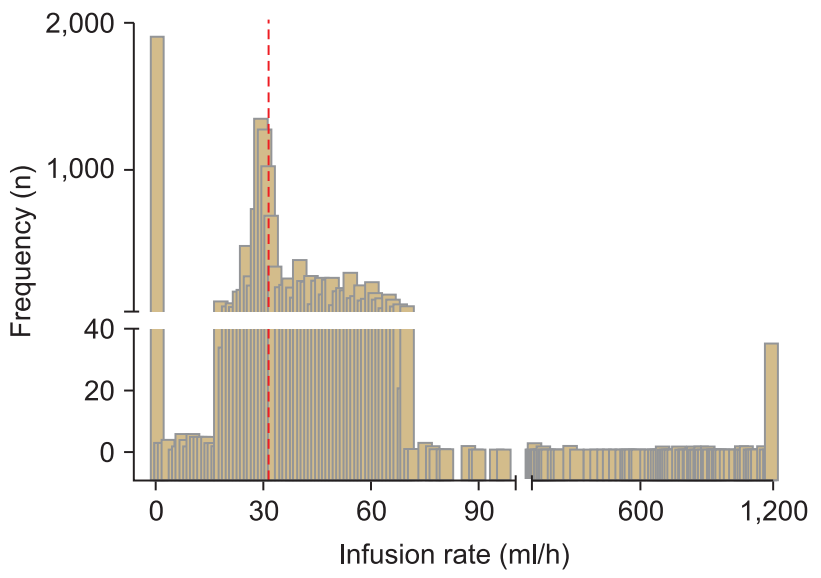

Fig. 2. Frequency distribution of infusion rates during propofol administration using a PION TCI pump from the induction of anesthesia to the time of the last blood sampling. The vertical red dotted line shows median frequency. TCl: target-controlled infusion. 
(28-46) $\mathrm{ml} / \mathrm{h}$. Mean Rate mea $_{\text {(SD) }}$ was $32.4 \pm 0.6 \mathrm{ml} / \mathrm{h}$. The infusion rate deviation as calculated by the gravimetric method at the representative infusion rate was $4.5 \pm 1.6 \%$.

\section{DISCUSSION}

An infusion pump is a medical electrical (ME) device to regulate the flow of liquids into the patient under pressure generated by the pump. A syringe pump is a type of infusion pump which performs controlled infusion of liquids into the patient by one or more single action syringes. The international standard for evaluating the accuracy of ME equipment covers only four flow types of the infusion pump: continuous infusion, noncontinuous infusion, discrete delivery of a bolus, and profile pump [8]. TCI is a flow type of infusion pump but is not yet considered.

In general, the accuracy of the TCI delivery system is assessed through the difference between the target concentration $\left(C_{p}\right)$ and the measured concentration $\left(C_{m}\right)$, where a performance error $\left(=\frac{C_{m}-C_{p}}{C_{p}}\right)$ is calculated for each measurement. According to several studies, median performance error (MDPE, bias) < 10-20 and median absolute performance error (MDAPE, inaccuracy) $<20-30$ are considered clinically acceptable [12-15]. MDPE represents the average overshoot or undershoot of the system, and an MDAPE of $25 \%$ indicates that one-half of the plasma concentrations will be within $25 \%$ of the target, and one-half will be outside that range. If the infusion rate deviation of the PION TCI pump is less than 5\%, this means that there is a difference of about $1.5 \mathrm{ml} / \mathrm{h}$ when administered at a rate of $31 \mathrm{ml} / \mathrm{h}$. Such a difference (propofol $15 \mathrm{mg}$ difference for $1 \mathrm{~h}$ ) does not have a significant effect on the plasma concentration of propofol. In other words, the effect of pump inaccuracies on the inaccuracy of TCI system is limited, thus confirming that the main cause of inaccuracy is pharmacokinetic variability.

In terms of pump inaccuracy, faster infusion rate and smaller size syringe lead to smaller errors induced by start-up delay in administration of the drug [16]. In a previous study, cumulative error rates of TCI pumps at $30 \mathrm{~min}$ after TCI initiation at plasma concentration of $0.5 \mu \mathrm{g} / \mathrm{ml}$ were $-1 \%$ to $-13 \%$ [17]. Maintaining a minimum of $10 \mathrm{~min}$ at a constant rate might be considered to be a relatively short time to evaluate the accuracy of the pump. Some infusion pump manufacturers include trumpet curves in their user manuals, in which the trumpet curve is defined as the maximum positive and negative percentage deviation from the expected dose relative to the time interval of infusion, for a set infusion rate [8]. The percentage error is the largest at the beginning of the administration and becomes smaller as the time for maintaining the constant rate becomes longer. After approximately 10 min, large fluctuations in the percentage error are reduced, resulting in a relatively constant error rate [8].

The accuracy of the TCI pump may be evaluated by a simulation method rather than the gravimetric method. The volume of drug administered to maintain a constant target concentration over a period of time can be calculated using nonlinear mixed effects modeling (NONMEM). However, NONEM simulations do not reflect the actual pump infusion rate nor do they consider the speed limit of 1,200 ml/h of the TCI pump. It is also impossible to comply with the international standard which stipulates that the accuracy of ME equipment should be evaluated by the gravimetric method as a gold standard. Therefore, to apply the gravimetric method, we had to derive a representative infusion rate from a previous study [6].

This study has some limitations which must be addressed. One limitation is that the infusion rate (which represents TCI mode) was not fixed to a single value. The representative infusion rate will vary with the pharmacokinetic model, the target concentration, and period over which the target concentration is maintained. In this study, the infusion rate deviation was $4.5-8.6 \%$ within the dose rate range of 29-34 $\mathrm{ml} / \mathrm{h}$, translating to a difference of $\sim 1.5-2.6 \mathrm{ml} / \mathrm{h}$. For propofol, this is not a dose that would cause clinically significant changes. Therefore, even if the value representing the TCI mode changes, the same result would be obtained: that the proportion of the inaccuracy of the TCI pump contributing to the inaccuracy of the TCI system is insignificant. Another limitation is that the method proposed in this study does not directly evaluate the accuracy of pumps operating in TCI mode. To date, however, there is no accuracy criterion for TCI mode operation of syringe pumps based on international standards, which is why we tried to suggest an alternative method for such evaluation. Although this method needs further improvement and adaptations, we believe that this may function as a viable method for objectively evaluating the accuracy of a pump in TCI mode.

In conclusion, the contribution of the TCI pump to the in- 
accuracy of the TCI system is insignificant.

\section{ACKNOWLEDGMENTS}

This study was supported by a grant (18011083) from the Korea Research Institute of Standards and Science, Daejeon, Republic of Korea, under the project "Establishment of measurement standards for medical metrology." We thank Dr. Joon Seo Lim from the Scientific Publications Team at Asan Medical Center for his editorial assistance in preparing this manuscript.

\section{CONFLICTS OF INTEREST}

No potential conflict of interest relevant to this article was reported.

\section{ORCID}

Il Doh: https://orcid.org/0000-0002-1639-7730

Seok Hwan Lee: https://orcid.org/0000-0003-2477-365X

Yong-Hun Lee: https://orcid.org/0000-0002-1724-7996

Bokyoung Jeon: https://orcid.org/0000-0003-3280-8429

Gyu-Jeong Noh: https://orcid.org/0000-0002-1964-9294

\section{REFERENCES}

1. Absalom AR, Glen JI, Zwart GJ, Schnider TW, Struys MM. Targetcontrolled infusion: a mature technology. Anesth Analg 2016; 122: 70-8.

2. Struys MM, De Smet T, Glen JI, Vereecke HE, Absalom AR, Schnider TW. The history of target-controlled infusion. Anesth Analg 2016; 122: 56-69.

3. Absalom AR, Mani V, De Smet T, Struys MM. Pharmacokinetic models for propofol--defining and illuminating the devil in the detail. Br J Anaesth 2009; 103: 26-37.

4. Park JH, Choi SM, Park JH, Lee KH, Yun HJ, Lee EK, et al. Population pharmacokinetic analysis of propofol in underweight patients under general anaesthesia. Br J Anaesth 2018; 121: 559-66.

5. Ki SH, Rhim JH, Park JH, Han YJ, Cho YP, Kwon TW, et al. Quantitative analysis of the effect of end-tidal carbon dioxide on regional cerebral oxygen saturation in patients undergoing carotid endarterectomy under general anaesthesia. Br J Clin Pharmacol
2018; 84: 292-300.

6. Yi JM, Doh I, Lee SH, Kim SY, Lee YH, Lee EK, et al. Predictive performance of a new pharmacokinetic model for propofol in underweight patients during target-controlled infusion. Acta Anaesthesiol Scand 2019; 63: 448-54.

7. Varvel JR, Donoho DL, Shafer SL. Measuring the predictive performance of computer-controlled infusion pumps. J Pharmacokinet Biopharm 1992; 20: 63-94.

8. International Electrotechnical Commision. IEC 60601-2-24:2012. Medical electrical equipment - part 2-24: particular requirements for the basic safety and essential performance of infusion pumps and controllers. 2nd ed. Geneva, International Electrotechnical Commision. 2012.

9. Lee SH, Kang W, Chun S. Dynamic behavior analysis of drug delivery devices using a dynamic gravimetric method. Flow Meas Instrum 2018; 62: 105-12.

10. Choi BM, Lee HG, Byon HJ, Lee SH, Lee EK, Kim HS, et al. Population pharmacokinetic and pharmacodynamic model of propofol externally validated in children. J Pharmacokinet Pharmacodyn 2015; 42: 163-77.

11. International Organization for Standardization. ISO 4185: 1980. Measurement of liquid flow in closed conduits--weighing method. Geneva, ISO. 1980.

12. Glen JB, Servin F. Evaluation of the predictive performance of four pharmacokinetic models for propofol. Br J Anaesth 2009; 102: 626-32.

13. Lee SH, Park HW, Kim MJ, Noh MH, Yoon HS, Choi BM, et al. External validation of pharmacokinetic and pharmacodynamic models of microemulsion and long-chain triglyceride emulsion propofol in beagle dogs. J Vet Pharmacol Ther 2012; 35: 329-41.

14. Vereecke HE, Eleveld DJ, Colin P, Struys MM. Performance of the Eleveld pharmacokinetic model to titrate propofol in an obese Japanese patient population. Eur J Anaesthesiol 2016; 33: 58-9.

15. Lee YH, Choi GH, Jung KW, Choi BH, Bang JY, Lee EK, et al. Predictive performance of the modified Marsh and Schnider models for propofol in underweight patients undergoing general anaesthesia using target-controlled infusion. Br J Anaesth 2017; 118: 883-91.

16. Neff SB, Neff TA, Gerber S, Weiss MM. Flow rate, syringe size and architecture are critical to start-up performance of syringe pumps. Eur J Anaesthesiol 2007; 24: 602-8.

17. Adapa RM, Axell RG, Mangat JS, Carpenter TA, Absalom AR. Safety and performance of TCI pumps in a magnetic resonance imaging environment. Anaesthesia 2012; 67: 33-9. 